\title{
MEDICINE PRESCRIBING PATTERN OF DERMATOLOGY OUTPATIENT DEPARTMENT IN A TERTIARY LEVEL HOSPITAL AT DHAKA CITY
}

\author{
SARKER SK ${ }^{1}$, ALI CM ${ }^{2}, \mathrm{KHAN} \mathrm{MI}^{3}$, RAHMAN H ${ }^{4}$, RAHMAN KA ${ }^{5}$
}

\begin{abstract}
Objective: The objective of the present study was assessing prescribing pattern of medicine in dermatology out patient department (OPD) in Dhaka Medical College Hospital.

Study design: Cross-sectional descriptive study and data was collected by systemic sampling technique.

Setting: The study was carried out at dermatology OPD in Dhaka Medical College Hospital during the month of March 2011.

Main outcome measure: Major therapeutic agents, percentage of drug prescribed from essential drug list (EDL) of Bangladesh, polypharmacy

Results: Total 100 prescriptions were selected for the study. Among the patients attended at OPD 59 were male and 41 were female and mean age (yrs) was $26 \pm 18$ SD. Most common prescribed antihistamine was chlorpheniramine maleate (88\%), scabicidal agents was permethrin (84\%), corticosteroid was betamethasone (35\%), combined corticosteroid and antimicrobial agents was clobetasol with neomycin plus nystatin (30\%), antifungal was fluconazole (26\%) and antibiotic was cloxacillin (50\%). Mean number of medicine per prescription was $2.7 \pm 0.847 \mathrm{SD}$. Polypharmacy (More than 3 medicines prescribed in a single diagnosis) was 14\%. On an average 70\% drugs were prescribed from essential drug list of Bangladesh.
\end{abstract}

Conclusion: Though this study had some limitations, the results of the study reflect some prescribing pattern of medicines in dermatology OPD in tertiary level hospital at Dhaka city.

Key words: Prescribing pattern, Dermatology OPD

J Dhaka Med Coll. 2012; 21(1) : 66-68.

\section{Introduction}

Drugs play an important role in protecting, maintaining and restoring health. Prescription writing is a science and an art, as it conveys the message from the prescriber to the patient 1. Principles of good prescribing are based on sound knowledge and understanding of the pathophysiology of disease to be treated, and the knowledge of risks and benefits of the medicine $e^{2,3}$. The standard treatment guidelines and essential drugs are the basic tools for assisting health professionals to choose the most appropriate medicine for the given patient with a given condition. It should be followed by the appropriate use of the selected medicine ${ }^{4}$. The patterns of drug use in a hospital setting need to be monitored intermittently in order to analyze their rationality and to offer feedback and/or suggestions to drug prescribers so as to enable and effect suitable modifications in prescribing pattern to increase the therapeutic benefits and reduce adverse effects ${ }^{1}$. The present study was conducted to identify the prescription trend of various dermatological drugs in the out patient department (OPD) of a tertiary level hospital at Dhaka city.

\section{Objective \\ General objective}

The objective of the present study was assessing prescribing pattern of medicine in dermatology

1. Dr. Sujit Kumar Sarker, Assistant Professor, Department of Pharmacology, DMC, Dhaka

2. Dr. Chowdhury Mohammad Ali, Professor, Department of Dermatology, DMC, Dhaka

3. Dr. Md. Ismail Khan, Professor, Department of Pharmacology, DMC, Dhaka

4. Dr. Hasanur Rahman, Assistant Professor, Department of Pharmacology, DMC, Dhaka

5. Dr. Kazi Afzalur Rahman, Lecturer, Department of Pharmacology, DMC, Dhaka

Correspondence : Dr. Sujit Kumar Sarker, Assistant Professor, Department of Pharmacology, DMC, Dhaka 
out patient department (OPD) in Dhaka Medical College Hospital.

Specific objectives

1. To observe major therapeutic agents prescribed in dermatology OPD.

2. To measure percentage of drugs prescribed from essential drug list.

3. To measure the degree of polypharmacy.

\section{Methodology}

The present study was aimed at identifying the prevailing prescription trend of various dermatological drugs in the out patient department (OPD) of a tertiary level hospital. The short-term study was conducted at dermatology OPD in Dhaka Medical College Hospital, Dhaka during the month of March 2011. The study was a cross-sectional descriptive study and systemic sampling technique was used for prescription collection. All the prescriptions written in dermatology OPD during one week period were collected and sorted out accordingly. Among the prescriptions 100 were finally selected for the analysis. Each prescription was given a serial number, the drugs prescribed were coded and information were carefully recorded. In this study polypharmacy was defined as more than 3 medicine prescribed in a single diagnosis. There was also some inclusion criteria: a.prescription with single diagnosis b.prescription without mentioned any diagnosis or clinical feature and exclusion criteria: a.prescription with more than one diagnosis.

\section{Results}

Among the prescribed outdoor prescriptions during the study period, 100 prescriptions were selected for the study. Among the patients attended at OPD 59 were male and 41 were female and mean age (yrs) was 26. Most common therapeutic drug group was antihistamine followed by scabicidal agents, corticosteroid, combined steroid and antimicrobial preparation and antifungal drugs. Most common prescribed antihistamine was chlorpheniramine maleate, scabicidal agents was permethrin, corticosteroid was betamethasone, combined corticosteroid and antimicrobial agents was clobetasol with neomycin plus nystatin, antifungal was fluconazole, antibiotic was cloxacillin, and among the other groups vitamin-E and Ranitidine were most common. Minimum number of medicine per prescription was 1 and maximum number of medicine per prescription was 5. Polypharmacy (More than 3 medicine prescribed in a single diagnosis) was $14 \%$. On an average $70 \%$ drugs were prescribed from essential drug list of Bangladesh.

\section{Table-I}

Demographic characteristics

\begin{tabular}{lc}
\hline Age (yrs) & Mean \pm SD: $26 \pm 18$ \\
\hline Sex & Male (59), Female (41) \\
\hline
\end{tabular}

\section{Table-II}

Major therapeutic agents prescribed in various drug groups

\begin{tabular}{ll}
\hline Category of drug & Major therapeutic agents (\%) \\
Scabicidal agents & Permethrin (84), Benzylbenzoate (13) \\
Antifungal drugs & Fluconazole (26), Ketoconazole (22) \\
Antibiotics & Cloxacillin (50), Flucloxacillin (14) \\
Corticosteroid & Betamethasone (35), Clobetasol (30) \\
Corticosteroid with Antimicrobial & Clobetasol+Neomycin+Nystatin (30), \\
& Betamethason+Neomycin (24), \\
& Triamcinolone+Econazole (24) \\
Antihistamine & Chlorpheniramine maleate (88), \\
& Fexofenadine(5) \\
\hline
\end{tabular}


Table-III

Number of medicine per prescription

\begin{tabular}{ll}
\hline Minimum number of medicine & 1 \\
Maximum number of medicine & 5 \\
Number of medicine (Mean $\pm \mathrm{SD}$ ) & $2.7 \pm 0.847$ \\
$\begin{array}{l}\text { Polypharmacy (More than } 3 \mathrm{~m} \\
\text { edicine prescribed in a single }\end{array}$ & $14 \%$ \\
$\begin{array}{l}\text { diagnosis) } \\
\text { Percentage of medicine prescribed } \\
\text { from essential drug list }\end{array}$ & Mean $\pm \mathrm{SD}:$ \\
of Bangladesh & $69.95 \pm 32.195$ \\
\hline
\end{tabular}

\section{Limitations of the study}

The present study had some limitations: 1.Conducted in a single hospital, 2.Small sample size, 3.Insufficient fund.

\section{Conclusion}

Drug therapy is the most commonly used method in the treatment of disease. So, periodic evaluation of prescribing pattern is necessary to improve prescribing standard, which may play an important role in the health care delivery system.

\section{Acknowledgement:}

The authors are grateful to Department of Skin \& VD, Dhaka Medical College Hospital and Bangladesh Medical Research Council (BMRC) for providing support to carry out the study.

\section{References}

1. Kumar MA, Noushad PP, Shailaja K, Jayasutha $\mathrm{J}$, Ramasamy C. A study on drug prescribing pattern and use of corticosteroids in dermatological conditions at a tertiary care teaching hospital. Int J Pharma Sci Rev Res 2011; 9(2): 132-5.

2. Grahame-Smith DG, Aronson JK. Principles of prescribing and how to write prescriptions. Oxford textbook of clinical pharmacology and drug therapy. $3^{\text {rd }}$ ed. New York: Oxford University Press; 2002. p.173-88.

3. Reid JL, Rubin PC, Whiting B. Drug prescription: Legal and practical aspects. In: Reid JL, Rubin PC, Whiting B, eds. Lecture notes on clinical pharmacology. $5^{\text {th }}$ ed. London: Blackwell Science Ltd; 1998.

4. Khan N A, Abid M, Maheshwari K K, Kaviarasan P K , Mohanta G P. Antibiotic prescribing pattern in department of dermatology of a teaching hospital in Tamil Nadu. Indian J Pharm Pract 2010; 3(3): 18-21. 